\title{
Estado atual do transplante renal no Brasil e sua inserção no contexto mundial
}

\author{
Renal transplantation in Brazil and its insertion in the global context
}

\author{
Affonso Piovesan ${ }^{1}$, William Carlos Nahas²
}

Piovesan A, Nahas WC. Estado atual do transplante renal no Brasil e sua inserção no contexto mundial / Renal transplantation in Brazil and its insertion in the global context. Rev Med (São Paulo). 2018 maio-jun.;97(3):334-9. $\begin{array}{ll}\text { RESUMO: Comparado aos demais países do mundo, o Brasil } & \text { Legislação como assunto; Estatística como assunto; Brasil/ } \\ \text { ocupa o segundo lugar em número de transplantes renais por ano. } & \text { epidemia. }\end{array}$ Considerando, entretanto, suas dimensões continentais, quando se analisa o número de transplantes por milhão de população, ocupa apenas o trigésimo terceiro lugar. Muitos fatores contribuem para este fato. A legislação que regulamenta doação de órgãos e transplantes no Brasil é bastante recente e foi criada com quase 10 anos de atraso quando comparado com outros países que ocupam primeiras posições na lista de efetividade de sistemas de captação. Uma enorme heterogeneidade na distribuição regional de centros de transplantes com cerca de $25 \%$ dos estados brasileiros com atividade mínima ou nula em termos destes procedimentos é também motivo de preocupação. Observa-se uma baixa efetividade dos mecanismos de procura de órgãos com índices de notificação de potenciais doadores falecidos muito baixos na maior parte do país. O pouco conhecimento da população sobre o conceito e segurança do diagnóstico de morte encefálica e do processo de doação, fazem com que, apesar do uso de critérios bastante rigorosos para este diagnóstico, a principal causa da não conversão de doador potencial para doador efetivo, seja a recusa familiar. Em termos de sobrevida do enxerto e do paciente, os índices brasileiros são comparáveis a centros norte americanos e europeus. A taxa de sobrevida de cinco anos do enxerto é de $86 \%$ para doador vivo e $73 \%$ para falecido. A sobrevida de cinco anos é de $94 \%$ para receptores de rins de doador vivo e de $86 \%$ para doador falecido. Enquanto países europeus e os Estados Unidos procuram por estratégias alternativas para aumentar o número de transplantes renais como o uso de doadores em parada cardíaca ou a realização de transplantes $\mathrm{ABO}$ incompatíveis, o Brasil parece ter muito a progredir simplesmente investindo em estratégias para tornar o atual modelo mais eficiente.

Palavras-chave: Transplante de rim; Transplante de rim/ estatística \& dados numéricos; Transplante de rim/legislação \& jurisprudência; Sistemas de saúde/legislação \& jurisprudência;

ABSTRACT: Brazil is the second country in the word in terms of absolute number of renal transplants per year. However, considering its continental dimensions and total population, it occupies only the 33th place in terms of number of procedures per million of habitants. Many factors contribute for this fact. Brazilian legislation regarding organ transplantation is recent and was created with an average delay of 10 years compared to countries in the top of the efficiency list. Also, an enormous heterogeneity in distribution of renal transplant centers among Brazilian states also is a point of concern and in almost $25 \%$ of them there is none or only a few number of these procedures. In addition, a low rate of potential deceased donors notification aggravate this situation. Another point is that there is poor understanding of the population in regards to the brain death concept and deceased donation process lead to a low rate of conversion from a potential to an effective donor. In spite of using very rigid criteria to diagnosis of brain death, the major cause of this failure is family deny. In terms of patient and graft survival, Brazilian numbers are similar of United States and European centers. Five years graft survival rate is $86 \%$ for live donation and $73 \%$ for deceased. Five years recipient survival is $94 \%$ for live and $86 \%$ for deceased donors. While European countries and United States are looking for alternative strategies to increase number of renal transplantations as non heart beat and ABO incompatible donation, Brazil seams to have a lot to progress simply investing on strategies to make the actual model more efficient.

Keywords: Kidney transplantation; Kidney transplantation/ statistics \& numerical data; Kidney transplantation/legislation \& jurisprudence; Health systems/legislation \& jurisprudence; Legislation as topic; Statistical data; Brazil/epidemiology.

1. Hospital das Clinicas HCFMUSP, Faculdade de Medicina FMUSP, Universidade de Sao Paulo, Sao Paulo, SP, BR. Núcleo de Urologia do Hospital Sirio Libanês. Corpo Clínico do Hospital Alemão Oswaldo Cruz.

2. Divisão de Urologia, Hospital das Clínicas HCFMUSP, Faculdade de Medicina FMUSP, Universidade de Sao Paulo, Sao Paulo, Brasil. Professor Titular de Urologia. ORCID: https://orcid.org/0000-0002-7395-8370.

Endereço para correspondência: Affonso Piovesan. R. Itapeva, 490 cj 117. São Paulo, SP, BR. CEP: 05083130. Email: piovesan. med@hotmail.com 
$\mathrm{C}$ om aproximadamente 5700 transplantes renais realizados por ano, o Brasil é o segundo país em número de procedimentos no mundo. Perde somente para os Estados Unidos, com cerca de 18000, mas realiza cerca de $60 \%$ mais do que a França que ocupa o terceiro lugar. Comparado com outros países a América Latina, claramente ocupa posição de destaque com quase 3 vezes o número de transplantes realizados ao ano que a Argentina, com $1198^{* 1}$.

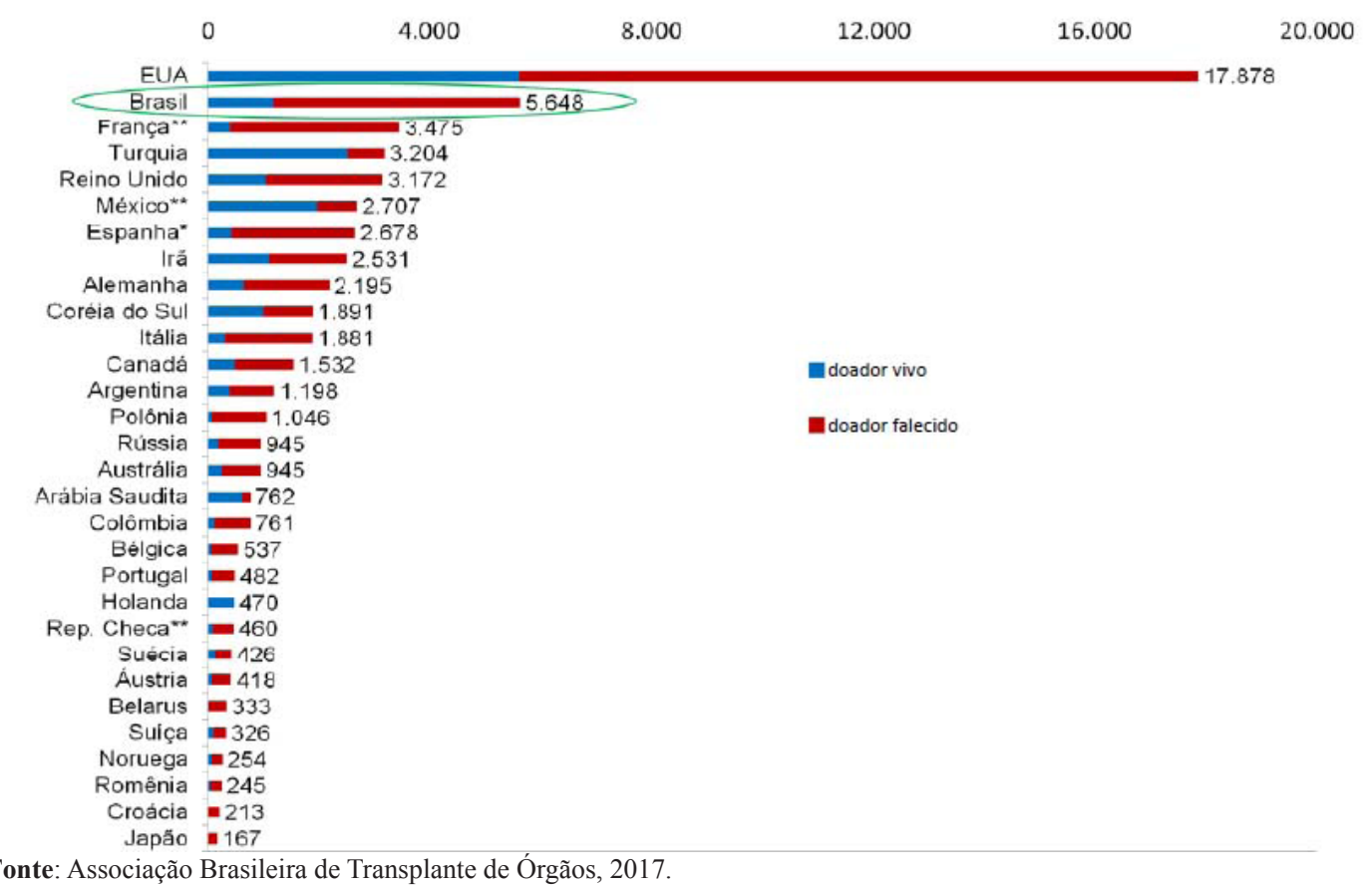

Figura 1. Número de transplantes renais realizados por ano no Brasil e demais países com sistemas de notificação de transplantes em 2015

Apesar desta posição de impacto, tal fato decorre devido às proporções continentais de nosso país e não à eficiência de nosso sistema de captação e de alocação de órgãos. Há muito o que evoluir neste sentido. Quando contextualizado de acordo com o número de transplantes renais realizados por milhar de população, o que, de fato, caracteriza a excelência de um país com relação a seu sistema de transplantes, ocupamos um modesto trigésimo terceiro lugar com 27,9 transplantes por mil habitantes, muito próximos de outros países da América Latina como Uruguai e Argentina e atrás da maior parte dos países Europeus ${ }^{1}$.

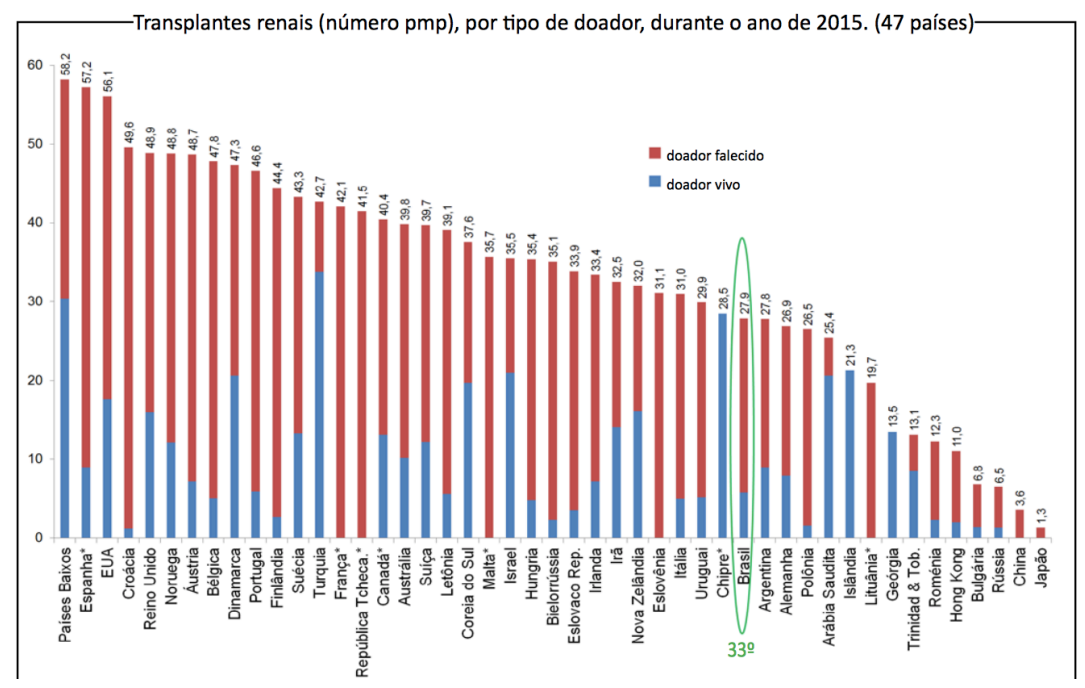

Fonte: Associação Brasileira de Transplante de Órgãos, 2017.

Figura 2. Transplantes renais por tipo de doador por milhão de população no Brasil e demais países com sistemas de notificação de transplantes em 2015 
Tal fato decorre principalmente de dois fatores: demora considerável em criação de legislação regulamentadora e de sua implementação e de uma péssima distribuição regional de serviços de transplantes em âmbito nacional.

Em países que encabeçam a lista de eficiência em transplante renal, as legislações regulamentadoras e a criação dos órgãos que permitiram a implantação do sistema de captação e distribuição de órgãos datam da segunda metade da década de 80. Nos Estados Unidos, por exemplo, as Organ Procurement Organizations (OPO) foram criadas em $1984^{2}$ e na Espanha, a Organizacion Nacional de Tranplantes (ONT) em 1989³. No Brasil, a resolução do Conselho Federal de Medicina número 1480, que veio a regulamentar o conceito de morte encefálica assim como a lei federal 10211, que regulamenta transplantes e doação de órgãos no país datam de $1997^{4}$, ano no qual é criado o
Sistema Nacional de Transplantes. Um atraso de quase 10 anos. Todos os transplantes realizados até então em nosso país foram feitos sem qualquer respaldo jurídico, colocando em situação bastante vulnerável as equipes pioneiras neste procedimento no Brasil.

Acompanhando a evolução do número de transplantes renais e sua distribuição conforme o tipo de doador, notamos que em países onde a organização do sistema de transplantes ocorreu mais cedo, houve um aumento importante do número de procedimentos realizados nos anos subsequentes até estabilização após aproximadamente $15 \operatorname{anos}^{5,6}$.

Tal fenômeno ocorreu em nosso país de maneira muito semelhante. Observa-se, a partir de 2002, um aumento grande no número anual de transplantes realizados, especialmente com doadores falecidos, até a sua estabilização a partir de $2013^{1}$.

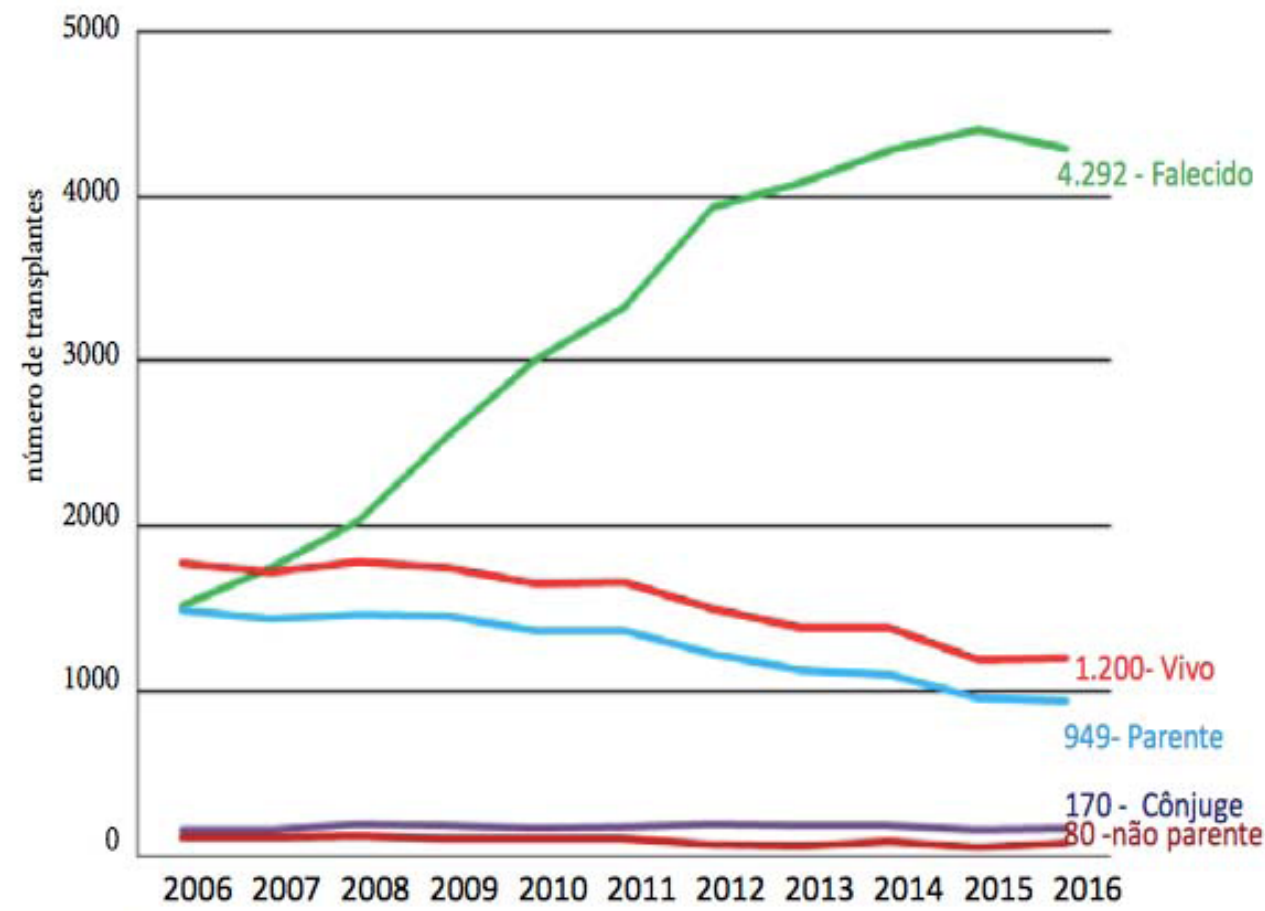

Fonte: Associação Brasileira de Transplante de Órgãos, 2017.

Figura 3. Número de transplantes renais realizados por ano segundo tipo de doador (2006 a 2016)

No Brasil, entretanto, ao contrário do observado em países de primeiro mundo, há condições que permitem acreditar que estes números têm ainda, alto potencial de crescimento. Analisando não a federação mas aspectos regionais, o que de pronto chama a atenção é a distribuição extremamente heterogênea dos serviços que realizam transplante renal. Com raras exceções como os estados de
Pernambuco e Ceará, estes procedimentos concentram-se quase exclusivamente nas regiões Sul e Sudeste. Observa-se ainda que em cerca de $25 \%$ dos estados brasileiros não se realiza ou se realiza uma quantidade ínfima de transplantes renais. Apesar de esforços realizados pelo Ministério da Saúde nos últimos governos, percebe-se que não houve mudança neste quadro na última década ${ }^{1}$. 


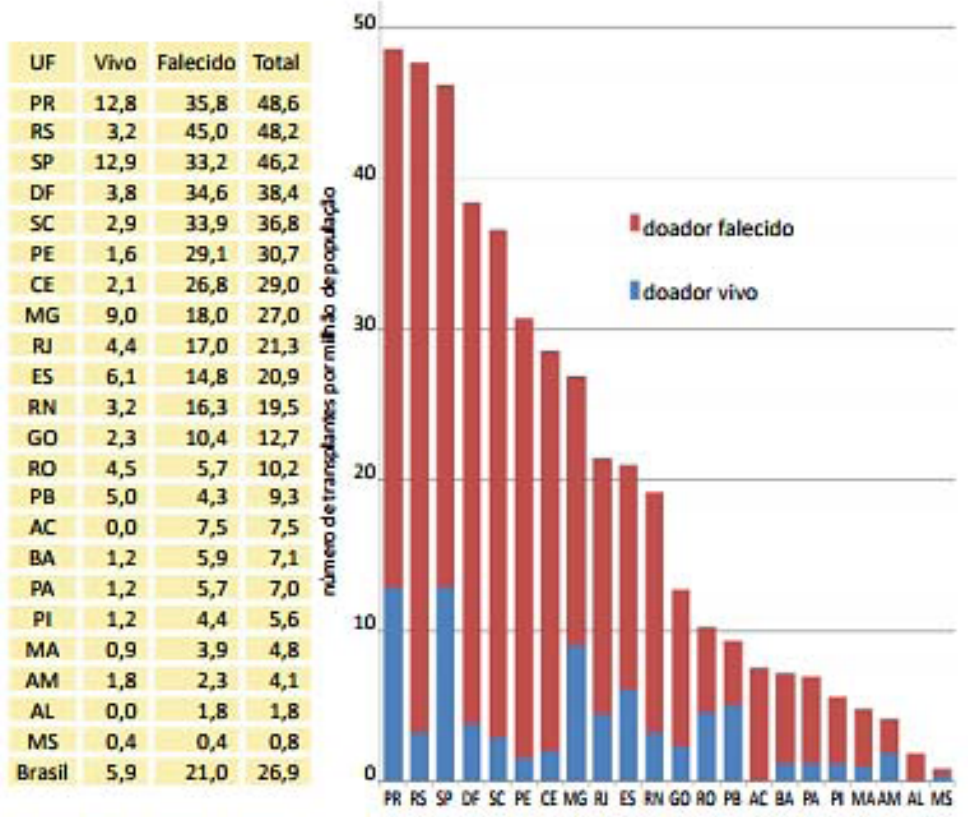

Fonte: Associação Brasileira de Transplante de Orgãos, 2017.

Figura 4. Número de transplantes renais realizados nos estados brasileiros, por milhão de população, em 2016 segundo tipo de doador

Outro ponto que merece atenção é a baixa efetividade do número de doações para transplantes renais com doador falecido. Mais uma vez as grandes diferenças regionais observadas a reste respeito. O Brasil ocupa o

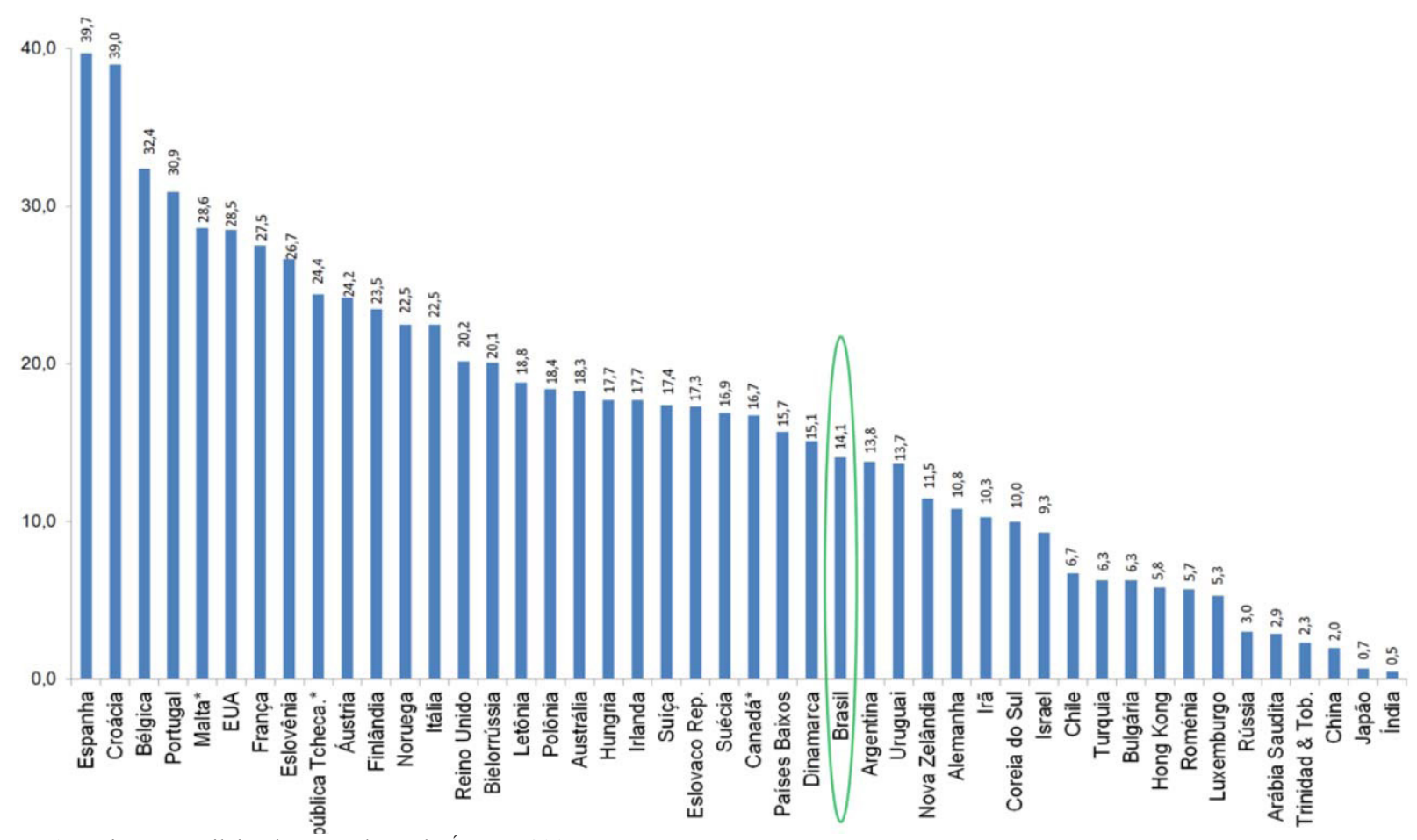

vigésimo sétimo lugar com relação ao número de doadores efetivos por milhar de população com 14,1 doações por mil habitantes. Os países com sistemas mais eficientes chegam a taxas acima de $30^{* 1}$.

Fonte: Associação Brasileira de Transplante de Órgãos, 2017.

Figura 5. Número de doadores efetivos, por milhão de população, no ano de 2015 no Brasil e demais países com sistemas de notificação de transplantes 
Apenas na região Sul o número de doadores efetivos por milhar de população chega próximo a níveis adequados. No restante do país o sistema de captação funciona com muito menos efetividade, tanto com relação ao número de notificações quanto ao número de doadores efetivos ${ }^{1}$.
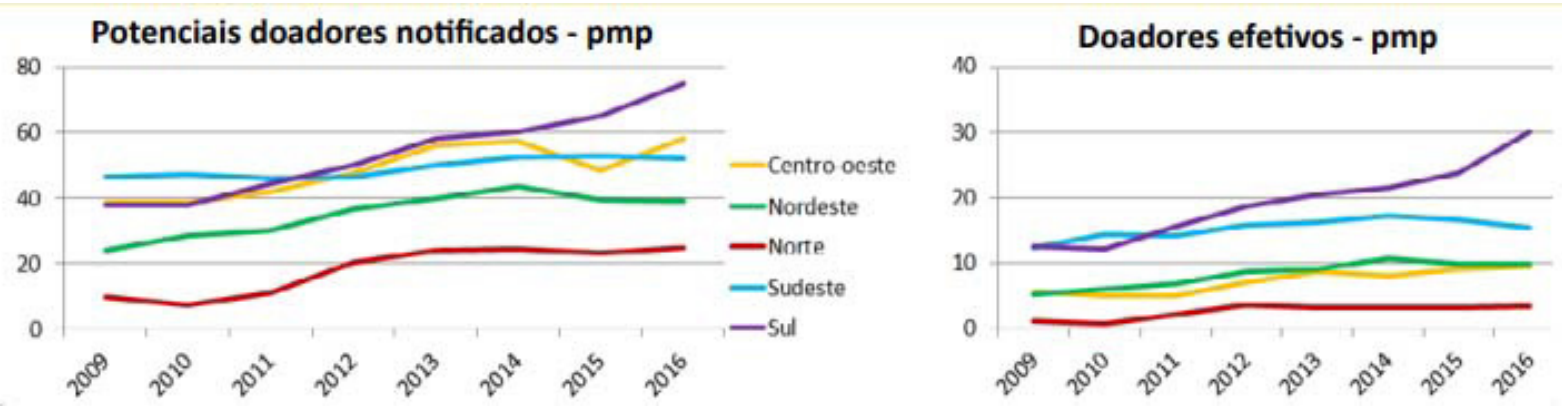

Fonte: Associação Brasileira de Transplante de Órgãos, 2017.

Figura 6. Número de doadores notificados e doadores efetivos por milhão de população segundo regiões brasileiras (2009-2015)

Somente cerca de $30 \%$ dos doadores potenciais se tornam doadores efetivos. Este número vem se mantendo estável nos últimos anos. A principal causa de não efetivação é a recusa familiar por insegurança com relação à irreversibilidade do coma. Curiosamente a legislação brasileira é uma das mais rigorosas no mundo para regulamentação do diagnóstico de morte encefálica. $\mathrm{Na}$ maior parte dos países europeus e na maior parte dos estados norte americanos (neste país a legislação é regional e não federal) se diagnostica morte encefálica por exame físico de pares cranianos, sem necessidade de qualquer exame complementar. No Brasil, além de ser necessário dois exames físicos realizados por equipes diferentes, não ligadas a serviços transplantadores, a lei prevê a confirmação por exame de imagem que comprove a ausência de irrigação ou atividade encefálica. A divulgação de tais critérios talvez seja de grande valia para incentivo à doação.

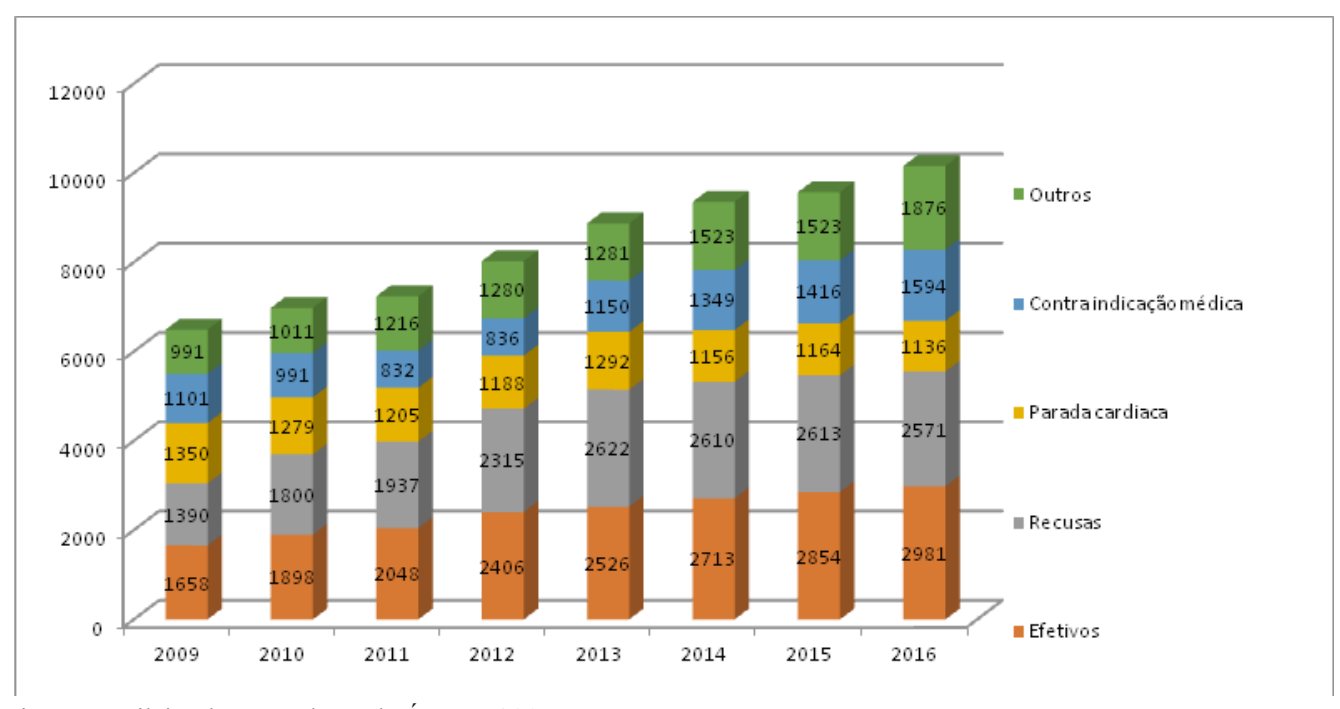

Fonte: Associação Brasileira de Transplante de Órgãos, 2017.

Figura 7. Número de doações potenciais, doações efetivas e razões de não efetivação no Brasil (2009-2015)

Quando se analisa a efetividade de nossos centros transplantadores por meio da sobrevida do enxerto e da sobrevida do receptor, observa-se índices muito próximos aos de países de primeiro mundo. Talvez esse fato se deva à concentração da maior parte dos procedimentos em poucos centros. Estes alcançam números de transplantes renais anuais semelhantes aos grandes centros americanos e europeus e reconhecida expertise mundial. Outro fator 
Piovesan A, Nahas WC. Estado atual do transplante renal no Brasil e sua inserção no contexto mundial.

a se considerar é o menor uso de doadores de critérios expandidos, ou seja, de rins não ideais, em nosso país quando comparado com outros países. Na Espanha, por exemplo, mais da metade dos doadores renais falecidos tem mais de $60 \operatorname{anos}^{* 7}$. Nos Estados Unidos cerca de $35 \%{ }^{* 5}$ enquanto no Brasil ao redor de $25 \%{ }^{*}$.

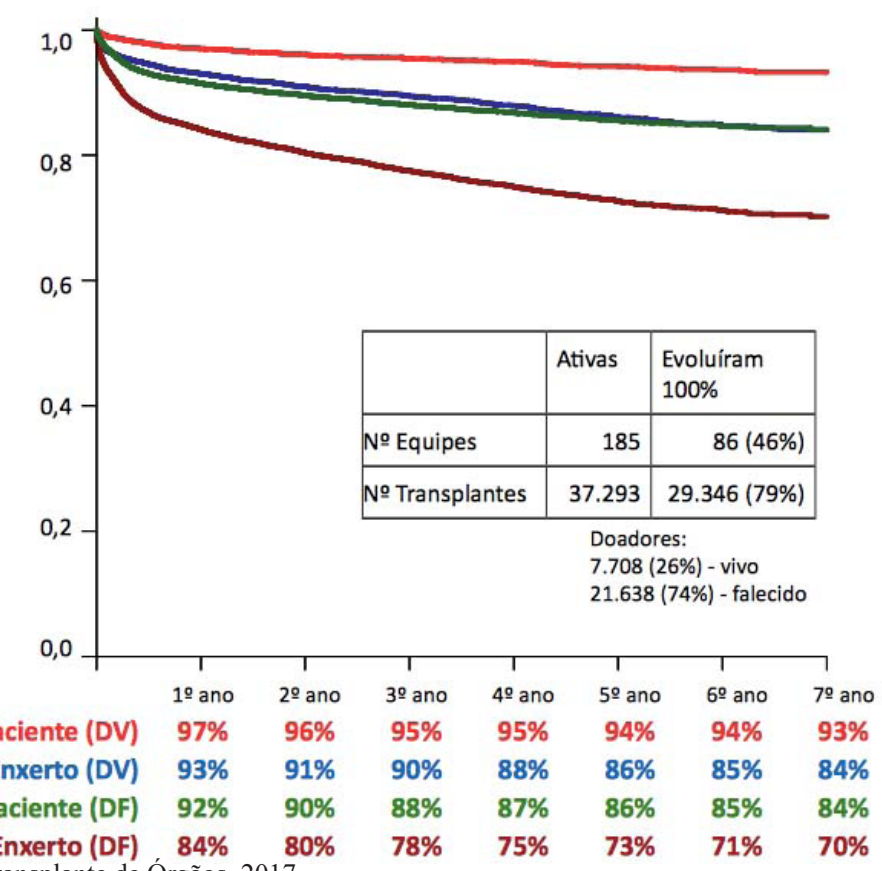

Fonte: Associação Brasileira de Transplante de Órgãos, 2017.

Figura 8. Curva de sobrevida do receptor e enxerto para transplante renal no Brasil: registro iniciado em 01/01/2010

Com relação a expectativas para o futuro, o Brasil acompanha a tendência mundial, observando-se aumento exponencial do número de pacientes em lista de espera para transplante renal. A maior expectativa de vida assim como a evolução dos sistemas de diálise aumenta o número de pacientes em insuficiência renal aguardando transplante. Como já foi exposto, o número de doações não acompanha este ritmo, permanecendo praticamente estável nos últimos anos.

Em vários países, parece se ter alcançado uma saturação do sistema de transplante tradicional, com necessidade de realização de procedimentos de maior risco como uso de doadores em parada cardíaca e ABO incompatíveis. No Brasil, não se realiza transplantes renais com doadores em parada cardíaca. Poucos centros iniciaram protocolos de transplantes com doadores ABO incompatíveis. O alto custo do processo de dessensibilização, parece ser, entretanto, um obstáculo à sua implementação em âmbito nacional. Por outro lado, ainda há muito campo para crescimento do número de transplantes renais sem a dependência de uso destes programas. $\mathrm{O}$ incentivo federal à descentralização e o aperfeiçoamento dos sistemas de captação são seguramente os meios mais eficazes para que as curvas se equilibrem.

Submetido em: 22.05 .18

Aceito em: 10.06 .18

\section{REFERÊNCIAS}

1. Associação Brasileira de Transplante de Órgãos. Dimensionamento dos transplantes no Brasil e em cada estado (2009-2016). RBT Registro Brasileiro de Transplantes. 2016;22(4) [citado maio 2018]. Disponível em: http://www.abto. org.br/abtov03/Upload/file/RBT/2016/RBT2016-leitura.pdf.

2. $\mathrm{n}$ PK. History of solid organ transplantation and organ donation. Crit Care Clin. 2009;25(1):165-84, ix. doi: 10.1016/j. ccc.2008.12.001.

3. Matesanz R, Miranda B. A decade of continuous improvement in cadaveric organ donation: the Spanish model. J Nephrol. 2002;15(1):22-8.

4. Legislação Brasileira sobre doação de órgãos humanos: Lei n.9.434, de 4 de fevereiro de 1997, que dispõe sobre a remoção de órgãos, tecidos e partes do corpo humano para fins de transplante e tratamento, e legislação correlata. Brasília: Câmara dos Deputados, Coordenação de Publicações; 2001. (Série fontes de referência, Legislação; n.41) [citado maio 2018]. Disponível em: https://www.idp.org.br/ componentdocman/doc_download/legislacao-brasileira-sobredoacao-de-orgaos.

5. OPTN/SRTR annual Data Report, 2004 [cited 2018 May]. Available from; https://www.srtr.org/reports-tools/srtroptnannual-data-report/.

6. Martín Escobar E. The Spanish Renal Registry: 2013 report and evolution from 2007-2013. Nefrologia. 2016;36(2):97120.

7. España. Organizacion Nacional de Transplantes. Datos Historicos [citado maio 2018]. Disponível em: https://reports. ont.es/datoshistoricos.aspx. 